Çukurova Üniversitesi Mühendislik Mimarlık Fakültesi Dergisi, 30(1), 141-150 ss., Haziran 2015

Çukurova University Journal of the Faculty of Engineering and Architecture, 30(1), pp. 141-150, June 2015

\title{
Farklı Regresyon Modelleri ile Patlatma Kaynaklı Yer Sarsıntısının Tahmin Edilmesi
}

\author{
Türker HÜDAVERDI ${ }^{* 1}$ \\ ${ }^{1}$ Ístanbul Teknik Üniversitesi, Maden Fakültesi, Maden Mühendisliği Bölümü, İstanbul \\ Geliş tarihi: 12.03.2015 Kabul tarihi: 05.05.2015
}

\section{Özet}

Patlatma kaynaklı yer sarsıntısı madenlerde gerçekleştirilen kaya patlatma operasyonunun en önemli çevresel etkilerindendir. Bu çalışmada ölçekli mesafe kavramına dayanan geleneksel yer sarsıntısı tahmin modelleriyle bir taş ocağında patlatma kaynaklı yer sarsıntısı tahmin edilmiştir. Patlatma tasarım parametrelerinin yer sarsıntısı oluşumundaki etkisi tartışılmıştır. Çok değişkenli regresyon analizi tekniği kullanılarak, patlatma tasarım parametrelerinin göz önüne alındığı yeni bir yer sarsıntısı tahmin denklemi geliştirilmiştir. Oluşturulan regresyon modelleri farklı hata kriterleri kullanılarak ayrıntılı olarak karşılaştırılmıştır. Çok değişkenli regresyon analizinin patlatma kaynaklı titreşimlerin tahmininde başarıyla kullanılabileceği ortaya konmuştur. Arazide görev yapan mühendislere sunulan farklı regresyon yaklaşımları yer sarsıntısı tahminindeki başarı oranını artıracaktır.

Anahtar Kelimeler: Çok değişkenli regresyon, Kaya patlatma, Yer sarsıntısı, Varyans analizi

\section{Prediction of Blast Induced Ground Vibration Using Various Regression Models}

\begin{abstract}
Blast induced ground vibration is one of the most important environmental effects of rock blasting operations in mines. In this research, blast induced ground vibration is predicted in a quarry by the models which use traditional scaled distance approach. Effect of the blast design parameters on blast vibrations is investigated. A new blast vibration prediction model, which consists of blast design parameters, is developed by multivariate regression analysis. Created regression models are compared using several error criterions in detail. It is proven that multivariate regression analysis can be used to predict blast induced vibrations successfully. Different regression analysis approaches will help site engineers increase accuracy of vibration prediction.
\end{abstract}

Keywords: Multivariate regression, Rock blasting, Ground vibration, Analysis of variance

\footnotetext{
* Yazışmaların yapılacağı yazar: Türker HÜDAVERDİ, İstanbul Teknik Üniversitesi, Maden Fakültesi, Maden Mühendisliği Bölümü, İstanbul. hudaverdi @itu.edu.tr
} 


\section{GíRiş}

Açık ocak maden işletmeciliğinde cevher ve örtü kazısı patlayıcılar kullanılarak geçekleştirilmektedir. Kaya patlatma faaliyetinin en önemli olumsuz çevresel etkileri yer sarsintısı ve hava şokudur. Özellikle patlatma kaynaklı yer sarsıntısı maden ocağından çok uzaktaki yapılarda dahi etkisini gösterebilmektedir. Birçok patlatma faaliyeti yapılara hasar verecek şiddette yer sarsıntısı oluşturmamasına rağmen, psikolojik faktörler devreye girmekte, titreşimlerden rahatsız olan çevre sakinleri nedeniyle üretim faaliyeti kesintiye uğramaktadır. Bu durum özellikle şehir merkezlerine yakın konumlanan taş ocakları için daha büyük önem arz etmektedir. Örneğin, bu çalışmanın gerçekleștirildiği İstanbul Cendere Bölgesi taş ocaklarında, genişleyen şehir nedeniyle yerleşim yerleri ocaklara gittikçe yaklaşmaktadır. İstanbul'un artan agrega ihtiyacı nedeniyle en verimli şekilde patlatma gerçekleștirme zorunluluğunun yanı sıra, en düşük çevresel etkiyi oluşturacak çalışma şartlarının oluşturulması gerekmektedir.

Patlatma kaynaklı yer sarsıntısı büyüklüğü genel olarak parçacık hızı kullanılarak ifade edilmektedir. Titreşim ölçümü gerçekleştiren sismograflar ile düşey, yatay ve boyuna olmak üzere parçacık hızı ölçülmekte, daha sonra en yüksek parçacık hızı (ppv) göz önüne alınarak tahmin modelleri oluşturulmaktadır. Parçacık hızının tahmin edilmesi için kullanılacak temel parametreler patlama yapılan nokta ile ölçüm istasyonu arasındaki mesafe (D) ve gecikme başına kullanılan maksimum patlayıcı madde miktarıdır (W). Yüksek yer sarsıntısı seviyelerinde öncelikli hedef patlatılan patlayıcı miktarını düşürmektedir. Çeşitli araştırmacılar ölçüm mesafesi ve patlayıcı miktarını kullanarak bir ölçekli mesafe tanımı yapmışlar ve yer sarsıntısını tahmin etmek için regresyon analizi önermişlerdir. Parçacık hızı ve ölçekli mesafe kullanılarak tek değişkenli regresyon tekniği ile yer sarsıntısı tahmin denklemi geliştirilmektedir. Regresyon analizinin katsayıları da patlatma ile ilgili jeolojik şartları ve arazi faktörlerini yansıtmaktadır. Genellikle tahmin denklemi oluştururken USBM'nin (ABD Madencilik Bürosu) önerdiği ölçekli mesafe yaklaşımı kullanılmaktadır [1]. Geliştirilen denklemlerin başarısı belirlilik katsayı $\left(\mathrm{R}^{2}\right)$ ile tanımlanmaktadır. Oysaki farklı araştırmacıların ölçekli mesafe yaklaşımı kullanılarak farklı regresyon denklemlerin incelenmesi gerekmektedir. Geliştirilen denklemler detaylı istatistiksel analiz yoluyla test edilmelidir.

Yer sarsıntısı tahmini için ölçüm mesafesi ve patlayıcı şarj miktarının yanı sıra, patlatma tasarım parametrelerinin de göz önüne alındığı eşitlikler geliştirilmelidir. Ölçekli mesafe kısır döngüsünün dışına çıkılmalıdır. Bu yolla yer sarsıntısı tahmin kapasitesinin artırılması mümkündür. Patlatma tasarım parametrelerinin değişiminin titreşimler üzerinde önemli etkisi mevcuttur. Örneğin dilim kalınlığının (B) aşırı seviyede olması patlatma enerjisinin tam olarak kayacı kırmak için kullanılamayarak aşırı yer sarsıntısı seviyelerine neden olması sonucunu doğurmaktadır [2]. Yine düzgün bir zemin elde etmek için uygulanan alt delme uzunluğunun (U) aşırı olması yüksek seviyede titreşimlerin oluşmasına sebebiyet verebilmektedir [3]. Konya [4] basamak yüksekliği (H) ve dilim kalınlığı oranını katılık olarak tanımlamış ve bu oranın artışıyla patlatma deliklerinin kıracağı kolonun gittikçe daha inceleceğini belirtmiş, atımları basamak yüksekliğine göre sınıflamıştır. Singh [5] aşırı s1kılama mesafesinin (T) patlayıcıyı patlatma kolunu içine hapsedeceğini ve bu durumun aşırı yer sarsıntına neden olacağını öne sürmüştür. Ayrıca, delikler arası mesafe (S) dilim kalınlığı oranının 1'den fazla olması gerektiğini, bu durumun parçalanma seviyesini artıracağını ve yer sarsıntısını düşüreceğini vurgulamıştır. $\mathrm{Bu}$ çalışmanın gerçekleştirildiği ocakta ölçülen patlatma tasarım parametreleri, Segarra ve diğerlerinden [6] değiştirilerek, izometrik bir yapıda, Şekil 1'de sunulmuştur.

Makalenin bundan sonraki bölümlerinde öncelikle çalışmanın gerçekleştirildiği taş ocağı tanıtılarak ölçülen veriler sunulacak, ardından ölçekli mesafe kavramı anlatılarak geleneksel yer sarsintıs1 tahmin yaklaşımları ortaya konacaktır. 4. Bölümde patlatma tasarım parametrelerinin de göz önüne alındığı yeni birçok değişkenli regresyon modeli sunulmuştur. Ardından geliştirilen farklı regresyon 
modelleri detaylı istatistiksel hata kriterleri ile karşılaştırılmıştır. Son bölümde sonuçlar kısaca tartışılmış, gelecek çalışmalar için önerilerde bulunulmuştur.

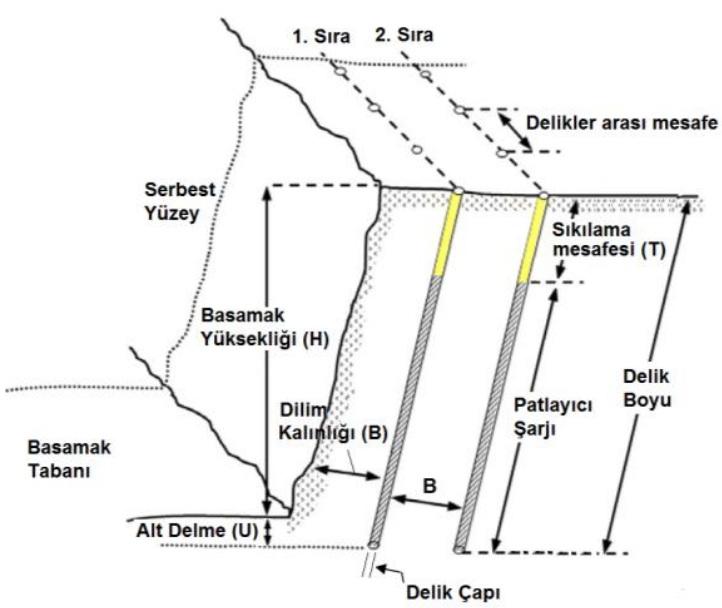

Şekil 1. Ocakta uygulanan patlatma tasarım parametreleri

\section{CALIŞMA YAPILAN SAHA VE ÖLÇÜMLER}

Yer sarsıntısı ölçümlerinin gerçekleştirildiği Akdağlar şirketine ait kumtaşı ocağı Kemerburgaz yakınlarındaki Cendere Vadisi'nde bulunmaktadır. $\mathrm{Bu}$ bölgedeki jeolojik yapı Trakya formasyonu olarak adlandırılmaktadır. Karbonifer yaşlı Trakya formasyonu İstanbul'un Avrupa yakasında sıklıkla görülmektedir. Formasyonun kalınlığ 600-1700 m arasındadır. Formasyon kumtaş1, şeyl, çakıl taşı, çamur taşı ardalanmalarından oluşmaktadır. $\mathrm{Bu}$ formasyonda en sik görülen kayaç tipi kumtaşıdır. Tabakalar arasında yer yer kireçtaşı ve konglomera katmanları görülmektedir. Trakya formasyonu genel olarak deformasyona uğramış, parçalanmış ve kıvrımlı bir yap1 göstermektedir. Genellikle açık renkli ve kalın tabakalı olan kumtaşının silis içeriği yüksektir. \%50-70 arası $\mathrm{SiO}_{2}$ içermektedir. Ocakta, açık renkli tabakalı kumtaşlarının yanı sıra yer yer ince laminalı, killi veya karbonatlaşmış kumtaşları görülmektedir.

Çalışma yapılan kısımda RQD değerleri zayıf orta (40-60) aralığında değişmektedir [7,8]. Patlatma ölçümlerinin yapıldığı bölümde, kayacın yoğunluğu 2,7 $\mathrm{gr} / \mathrm{cm}^{3}$ 'dür. Mohs sertliği 5-6 arasında değişmektedir ve ortalama porozitesi \%1,3'tür. Basınç dayanımı 81 MPA, çekme dayanımı 5,6 MPA, elastisite modülü 16,9 GPA'dır. Patlatma incelemeleri ocağın kuzey basamaklarında, belirli bir süre zarfinda uzun zamana yayılmadan gerçekleştirilmiştir. Çalışma sırasında kayaç özelliklerinde önemli bir değişime rastlanmamıştır. Ocak ilerledikçe veya ocağın belirli kısımlarında kayaç özelliklerinin nisbi olarak değişmesi mümkün olabilir. Ocak şartları değiştikçe gözlemlerin yenilenmesi gerektiği unutulmamalıdır. Ölçülen patlatma tasarım parametreleri ve yer sarsıntısı değerleri ile ilgili tanımlayıcı istatistikler Çizelge 1'de verilmiştir.

Çizelge 1. Ocakta ölçülen patlatma tasarım parametreleri ve titreşim ölçüm verileri

\begin{tabular}{|l|c|c|c|c|c|}
\hline Değişken & Minimum & Maksimum & Değişim Aralı̆̆ı & Ortalama & Standart sapma \\
\hline B (m) & 1,8 & 2,5 & 0,70 & 2,18 & 0,233 \\
\hline S (m) & 2 & 3 & 1 & 2,60 & 0,210 \\
\hline H (m) & 5,5 & 11 & 5,50 & 6,96 & 1,066 \\
\hline T (m) & 2 & 3 & 1 & 2,54 & 0,290 \\
\hline U (m) & 0,4 & 0,6 & 0,20 & 0,49 & 0,079 \\
\hline W (kg) & 73,99 & 227,27 & 153,27 & 113,86 & 31,995 \\
\hline D (m) & 55 & 245 & 190,0 & 126,79 & 52,572 \\
\hline ppv (mm/s) & 1,8 & 33,1 & 31,30 & 15,19 & 8,355 \\
\hline
\end{tabular}

B: Dilim kalınlığı, S: Delikler arası mesafe, H: Basamak yüksekliği, T: Sıkılama mesafesi, U: Alt delme, W: maksimum patlayıcı şarjı, D: titreşim ölçüm mesafesi, ppv: en yüksek parçacık hızı, izlenen atım sayısı (n): 39 . 
Ocaklarda düşük ve orta yükseklikteki basamaklarda patlatma faaliyeti gerçekleştirilmektedir. Patlatma deliklerinin çapı 89 mm'dir. Patlayıcı olarak ANFO kullanılmakta, ateşleme elektrikli kapsüller ile gerçekleştirmektedir. Yemleme olarak emülsiyon patlayıcı kullanılmaktır. Ocakta toplam 39 atım gözlenmiştir. Her atım için atım öncesi patlatma tasarım parametreleri ayrıntılı olarak ölçülmüştür. Titreşim ölçümü sırasında ölçüm mesafesi kayıt edilmiştir.

Patlatma kaynaklı yer sarsıntısını ölçmek için Instantel MiniMate Plus ${ }^{\mathrm{TM}}$ model titreşim ölçer cihaz kullanılmıștır. Cihaz 3 jeofon, mikrofon, hafıza ünitesi ve şarj edilebilir pil ünitesinden oluşmaktadır. Cihaz yer sarsıntısını $254 \mathrm{~mm} / \mathrm{s}$ hıza kadar ölçebilmektedir. Frekans aralığı 2-250 Hz arasındadır. Çözünürlük $0.127 \mathrm{~mm} / \mathrm{s}$, ölçüm hata payı +/- \%5 seviyesindedir. Çok sayıda ölçüm değerini cihazın hafıza ünitesinde depolamak mümkündür.

\section{3. ÖLÇEKLİ MESAFE KAVRAMI VE GELENEKSEL YER SARSINTISI TAHMIN YAKLAŞIMLARI}

Patlatma kaynaklı titreşimlerin tahmininde genellikle patlatma noktasından olan uzaklık ve gecikme başına patlayan şarj miktarı gözetilerek bir ölçekli mesafe tanımı yapılır. En sık kullanılan ölçekli mesafe yaklaşımlarından biri aşağıda verilen ABD Madencilik Bürosu'na -United States Bureau of Mines (USBM)-ait ölçekli mesafe yaklaşımıdır [9].

Ölçekli mesafe $S D=\frac{D}{\sqrt{W}}$

D: Patlatma yapılan lokasyon ile ölçüm istasyonu arasındaki mesafe $(\mathrm{m})$

$\mathrm{W}$ : $8 \mathrm{~ms}$ gecikme başına kullanılan maksimum patlayıcı miktarı $(\mathrm{kg})$

Her atım için ölçekli mesafe tespit edildikten sonra parçacık hızı değerleri kullanılarak tek değişkenli regresyon analiz gerçekleştirilir ve en yüksek parçacık hızını (ppv) tahmin eden bir denklem ortaya konur. Farklı araştırmacıların önerdiği ölçekli mesafe yaklaşımları Çizelge 2'de parantezler içinde görülmektedir. Regresyon analizi sonucu elde edilen $\mathrm{k}$, $\mathrm{n}$ ve $\mathrm{m}$ katsayıları, yer sarsıntısına etki eden jeolojik faktörleri içeren arazi katsayıları olarak tanımlanmaktadır [10].

Çizelge 2. En yüksek parçacık hızı tahmin denklemleri

\begin{tabular}{|l|l|}
\hline USBM [9] & $p p v=K \cdot\left(\frac{D}{\sqrt{W}}\right)^{n}$ \\
\hline Langefors-Kihlström [11] & $p p v=K \cdot\left(\frac{\sqrt{W}}{D^{3 / 4}}\right)^{n}$ \\
\hline Davies et al. [12] & $p p v=K \cdot D^{n} \cdot W^{m}$ \\
\hline Ambraseys-Hendron [13] & $p p v=K \cdot\left(\frac{D}{W^{1 / 3}}\right)^{n}$ \\
\hline Indian standards [14] & $p p v=K \cdot\left(\frac{W}{D^{2 / 3}}\right)^{n}$ \\
\hline CMRI [15] & $p p v=n+K \cdot\left(\frac{\sqrt{W}}{D}\right)^{2}$ \\
\hline
\end{tabular}

Diğer tahmin denklemlerinden nispeten farklı bir yap1 gösteren CMRI denklemi Hindistan'da bulunan Merkezi Madencilik Araştırma Enstitüsü Central Mining Research Institute- tarafindan geliştirilmiştir [15]. Çizelge 2'deki Davies ve diğerlerine [12] ait formül ise ölçekli mesafe kavramına başvurmadan ölçüm mesafesi ve patlayıcı miktarının kullanıldığ 1 regresyon analizini önermektedir. Geleneksel girdi parametrelerini kullanmakla birlikte, Davies ve diğ. denklemini başlangıç seviyesinde bir çok değişkenli regresyon denklemi olarak tanımlamak da mümkündür. Regresyon analizi ile elde edilen sonuçlar aşağıda Çizelge 3'de sunulmuştur. Görüldüğü üzere ilk dört denklemin belirlilik katsayısı $\left(R^{2}\right)$ birbirine yakındır. Indian standards denklemi en düşük belirlilik katsayısı değerini vermiştir. 
Çizelge 3. Regresyon analizi sonucu elde edilen arazi katsayıları

\begin{tabular}{|l|c|c|c|c|}
\hline Denklem & K & $\mathbf{n}$ & $\mathbf{m}$ & $\mathbf{R}^{\mathbf{2}}$ \\
\hline USBM [9] & 751,44 & $-1,701$ & & 0,765 \\
\hline Langefors-Kihlström [11] & 192,82 & 2,2462 & & 0,751 \\
\hline Davies et al. [12] & 855,07 & $-1,700$ & 0,805 & 0,764 \\
\hline Ambraseys-Hendron [13] & 2595,7 & $-1,672$ & & 0,758 \\
\hline Indian standards [14] & 0,9195 & 1,7057 & & 0,486 \\
\hline CMRI [15] & 200,22 & $-3,9688$ & & 0,695 \\
\hline
\end{tabular}

\section{4. ÇOK DEĞISSTENLİ REGRESYON ANALíi}

Çok değişkenli regresyon analizi için sırasıyla $\mathrm{W}$ ve D'nin yanı sıra B, S, H, T, U patlatma tasarım parametreleri bağımsız değişken olarak kullanılmıştır. Bağımlı değişken tahmin edilmek istenen en yüksek parçacık hızıdır. $\mathrm{Bu}$ parametrelerden en öne çıkanları belirlemek ve modele dahil etmek için adımsal regresyon tekniği kullanılmıştır. Adımsal regresyon analizinde regresyon denklemi adımlar halinde oluşturulur. İlk aşamada bağımlı değişkenle en yüksek korelasyona sahip bağımsız değişken denkleme dahil edilir. İkinci aşamada kalan değişkenler arasından bağımlı değişkenle en yüksek kısmi korelasyona sahip olan değişken, ilk bağımsız değişken kontrol edilerek denkleme eklenir. İşlem bu şekilde adımlar halinde devam eder. Her eklenen bağımsız değişken regresyonun $\mathrm{R}^{2}$ değerini artırır. İşlem artık bağımsız değişken eklemenin regresyonun $\mathrm{R}^{2}$ değerini değiştirmediği noktaya kadar veya tüm bağımsız değişkenler eklenene kadar devam eder [16, 17]. Adımsal regresyon tekniğiyle modele dahil edilecek önemli parametrelerin belirlenmesi yerbilimlerinde sıkça başvurulan bir yöntemdir. Malaki ve diğerleri [18] olası kömür patlamalarını tahmin edebilmek için adımsal regresyondan yararlanmışlardır. 25 adet jeolojik, jeometrik, jeomekanik parametre göz önüne alınmış, ardından adımsal regresyon ile 25 parametreden en önemli olanları tespit edilmeye çalışılmıştır. Chakraborty ve diğerleri [17] parçalanmaya etki eden parametreleri ana hatlarıyla belirlemek için parametrik bir çalışma gerçekleştirmiştir. Bu çalışmada da adımsal regresyon analizi yöntemi kullanılmıştır. Araştırmacıların göz önüne aldığı parametreler kayaç özellikleri, patlayıcı özellikleri ve patlatma tasarım parametreleridir.

Geliştirilen çok değişkenli adımsal regresyon modelinin özeti Çizelge 4'de sunulmuştur. Görüldüğü üzere adımsal regresyon modelinde parçacık hızı ile en yüksek kısmi korelasyona sahip ilk parametre modele 1. aşamada katılan ölçüm mesafesidir. $\mathrm{Bu}$ aşamada $\mathrm{R}^{2}$ değeri 0,692'dir. Daha sonra sırasıyla dilim kalınlığg (B) ve maksimum patlayıcı miktarı (W) modele dahil olmuştur. $\mathrm{R}^{2}$, 0,857 değerine ulaşmıştır. Her aşamada kısmi korelasyonu en yüksek parametre modele dahil olmuştur.

Çizelge 4. Çok değişkenli adımsal regresyon modelinin özeti

\begin{tabular}{|c|c|c|c|c|}
\hline Model & $\mathrm{R}$ & $\mathrm{R}^{2}$ & $\begin{array}{c}\text { Ayarlanmış } \\
\mathrm{R}^{2}\end{array}$ & $\begin{array}{c}\text { Tahmindeki } \\
\text { standart } \\
\text { hata }\end{array}$ \\
\hline 1 & 0,832 & 0,692 & 0,684 & 0,17860 \\
2 & 0,885 & 0,783 & 0,771 & 0,15213 \\
3 & 0,926 & 0,857 & 0,844 & 0,12531 \\
\hline
\end{tabular}

1. Bağımsız değişkenler: (sabit), D

2. Bağımsız değişkenler: (sabit), D, B

3. Bağımsız değişkenler: (sabit), D, B, W

Çizelge 5'de model dışı bırakılan değişkenler ve kısmı korelasyonlar verilmiştir. $\mathrm{Bu}$ çizelge ile adımsal regresyonunun nasıl gerçekleştirildiğini 
daha detaylı incelemek mümkündür. 1. Bağımsız değişken (D) modele dahil edildikten sonra, kısmi korelasyonlar incelendiğinde, bağımlı değişken ile en yüksek korelasyona sahip parametrenin 0,542 değeri ile dilim kalınlığı (B) olduğu görülür. B parametresi modele girdikten sonra 2 . aşamada en yüksek korelasyonu sağlayan maksimum patlayıcı madde miktarı (W) modele dahil olmuştur. Bundan sonra 3. aşamada geriye kalan 4 parametre incelenirse kısmi korelasyonun çok düşük olduğu görülür. Artık modele yeni parametre dahil etmeye gerek yoktur ve çok değişkenli regresyon denklemi tamamlanmıştır. Çizelge 5'deki beta katsayısı standardize edilmiş katsayılardır; farklı aşamalarda bağımsız değişenin rölatif önemini görmek için kullanılabilir. Kısmi korelasyonu yüksek parametrelerin aynı zamanda anlamlılık değerinin yüksek olması beklenebilir [19].

Çok değişkenli regresyon analizi sonucu elde edilen denklem aşağıda 2 No'lu denklem olarak sunulmuştur. Elde edilen belirlilik katsayısı $\left(\mathrm{R}^{2}\right)$ 0,857 mertebesindedir ve Çizelge 2'de sunulan geleneksel parçacık hızı tahmin denklemlerinden daha yüksektir. Adımsal regresyon en önemli parametrelerin modele dahil edilmesini sağlamış, en düşük sayıda bağımsız değişkenle model kurulmuştur. Tüm patlatma tasarım parametrelerinin modele dahil edilmesi durumunda elde edilecek $\mathrm{R}^{2}$ değeri 0,861 mertebesinde olacaktır. Bütün parametrelerin kullanılması model başarısında anlam oluşturacak önemli bir değişiklik yaratmayacaktır.

$$
\begin{aligned}
& p p v=252,348 \times B^{2,100} \times W^{0,811} \times D^{-1,774} \\
& \left(\mathrm{R}^{2}=0,857\right)
\end{aligned}
$$

Çizelge 6'da 2 No'lu çok değişkenli regresyon denkleminin varyans analiz Çizelgesu sunulmuştur. 'Kareler Toplamı' sütununun Regresyon kısmı; bağımlı değişkendeki değişimin açıklanan kısmını; artık bölümü ise regresyon modeli ile bağımlı değişkendeki açıklanamayan değişim miktarını göstermektedir. Bu Çizelgeya göre bağımlı değişkendeki değişimin \%85'den fazlası oluşturulan modelle açıklanmıştır. F istatistiği regresyon modelinin anlamlılığını test

\begin{tabular}{|c|c|c|c|c|c|}
\hline Model & Parametre & Beta & $\mathrm{t}$ & Anlamlılık & Kismi Korelasyon \\
\hline \multirow[t]{6}{*}{1} & B & 0,304 & 3,872 & 0,000 & 0,542 \\
\hline & S & 0,273 & 3,384 & 0,002 & 0,491 \\
\hline & $\mathrm{H}$ & 0,164 & 1,840 & 0,074 & 0,293 \\
\hline & $\mathrm{T}$ & 0,037 & 0,384 & 0,703 & 0,064 \\
\hline & $\mathrm{U}$ & 0,262 & 3,213 & 0,003 & 0,472 \\
\hline & $\mathrm{W}$ & 0,291 & 3,340 & 0,002 & 0,486 \\
\hline \multirow[t]{5}{*}{2} & $S$ & 0,056 & 0,363 & 0,718 & 0,061 \\
\hline & $\mathrm{H}$ & 0,117 & 1,501 & 0,142 & 0,246 \\
\hline & $\mathrm{T}$ & $-0,013$ & $-0,161$ & 0,873 & $-0,027$ \\
\hline & $\mathrm{U}$ & 0,057 & 0,435 & 0,666 & 0,073 \\
\hline & $\mathrm{W}$ & 0,293 & 4,250 & 0,000 & 0,583 \\
\hline \multirow[t]{4}{*}{3} & $\mathrm{~S}$ & 0,002 & 0,019 & 0,985 & 0,003 \\
\hline & $\mathrm{H}$ & $-0,034$ & $-0,443$ & 0,661 & $-0,076$ \\
\hline & $\mathrm{T}$ & 0,030 & 0,437 & 0,665 & 0,075 \\
\hline & $\mathrm{U}$ & 0,054 & 0,497 & 0,623 & 0,085 \\
\hline \multicolumn{6}{|c|}{ 1. Bağımsız değişkenler: (sabit), D } \\
\hline \multicolumn{6}{|c|}{ 2. Bağımsız değişkenler: (sabit), D, B } \\
\hline \multicolumn{6}{|c|}{ 3. Bağımsız değişkenler: (sabit), $\mathrm{D}, \mathrm{B}, \mathrm{W}$} \\
\hline
\end{tabular}

Çizelge 5. Model dışı bırakılan değişkenler ve kısmi korelasyonlar 
etmek için uygulanmaktadır. Eğer anlamlılık değeri 0,05 'in altındaysa, model tarafından açıklanan değişim şans eseri değildir. Diğer bir ifade ile, ppv ile bağımsız değişkenler arasında lineer ilişki olmadığını öne süren sıfır hipotezi \%5 anlamlılık düzeyinde reddedilir [20,21]. Çizelge 6' da görüldüğü üzere hesaplanan F değerine göre geliştirilen modelin anlamlı olduğu sonucu çıkmıştır.

\section{FARKLI REGRESYON ANALIZI SONUÇLARININ KARŞILAŞTIRILMASI}

Elde edilen farklı regresyon analizi yaklaşımlarının karşılaştırılması için ayrıntılı bir istatistiksel inceleme Çizelgesi kullanılmıştır. Tek bir doğruluk ölçüsü kullanıldığında kimi zaman sonuçlarda sapma olabilmektedir.

Çizelge 6. Çok değişkenli regresyon varyans analizi (ANOVA)

\begin{tabular}{|l|c|c|c|c|c|}
\hline & Kareler Toplamı & df & Ortalama Kare & F & Anlaml1lk \\
\hline Regresyon & 3,284 & 3 & 1,095 & 69,712 & 0,000 \\
\hline Artık & 0,550 & 35 & 0,016 & & \\
\hline Toplam & 3,833 & 38 & & & \\
\hline
\end{tabular}

$\mathrm{Bu}$ nedenle birden fazla doğruluk ölçütü kullanılmasında fayda vardır. Geliştirilen formüller kullanılarak 39 atım için ayrı ayrı en yüksek parçacık hızı değerleri hesaplanmıştır. Formüllerle hesaplanan değerler ile arazide ölçülen değerlerin karşılaştırılması hata analizinin temelini oluşturmaktadır. Kullanılan ilk iki hata ölçütü Ortalama Mutlak hata (OMH) -mean absolute error- ve hata kareleri ortalamasının karekökü (HKOK) -root mean square error- olarak adlandırılmaktadır. OMH ve HKOK ne kadar düşükse, tahminin o derece başarılı olduğu söylenebilir. $\mathrm{Bu}$ iki ölçüt arazide ölçülen ve regresyon denklemiyle tahmin edilen değerler arasındaki farkı gözeterek hesaplama yapmaktadır. Bunlardan farklı olarak Varyans Oranları Yüzdesi (VYO) -variance accounted for- tahmin hatası değerlerinin varyansı ile ölçüm verilerin varyansı kullanılarak hesaplanır. VYO yükseldikçe modelin başarısı artmaktadır. VYO'nun \%100 olması mükemmel bir model kurulduğunu, regresyon analizi ile tahmin edilen parçacık hızı değerlerinin hatasız olduğunu gösterir [22,23]. Formülle hesaplanan değerler ile ölçülen değerler arasındaki ilişki doğrusal regresyon kullanılarak da incelenmiştir. Çizelge 7'nin 4. sütunu formülle tahmin edilen değer ile gerçek değerler arasındaki korelasyonu vermektedir. Korelasyonun yükselmesi tahminin başarısını göstermektedir. 5 . sütun ise gerçekleştirilen tahminin standart hatasıdır. Son sütunda verilen $2 \mathrm{~mm} / \mathrm{s}$ 'den düşük hata ile tahmin sayısı, modelin hassas tahmin kapasitesini görmek için kullanılabilir.

$$
\begin{aligned}
& O M H=\frac{1}{n} \sum_{i=1}^{n}\left|y_{i}-x_{i}\right| \\
& H K O K=\sqrt{\frac{1}{n} \sum_{i=1}^{n}\left(y_{i}-x_{i}\right)} \\
& V Y O=\left(1-\frac{\operatorname{var}\left(y_{i}-x_{i}\right)}{\operatorname{var} y_{i}}\right) \times 100 \%
\end{aligned}
$$

$\mathrm{y}_{\mathrm{i}}=$ ölçülen parçacık hızı değeri $(\mathrm{mm} / \mathrm{s})$

$\mathrm{X}_{\mathrm{i}}=$ tahmin edilen parçacık hızı değeri $(\mathrm{mm} / \mathrm{s})$

$\mathrm{n}=$ örnek sayısı

Çizelge 7'de görüldüğü üzere bütün hata indisleri göz önünde alındığında, en başarılı denklem çok değişkenli regresyon denklemi olmuştur. $\mathrm{Bu}$ denklem parçacık hızını en düşük hata ile tahmin etmiştir. Çok değişkenli regresyon ile tahmin edilen parçacık hızı değerleri en yüksek korelasyonla gerçek değerlere yakındır. Çok değişkenli regresyon denklemi ile 21 atım $2 \mathrm{~mm} / \mathrm{s}$ 'den daha düşük bir hata ile tahmin edilmiştir. Çok değişkenli regresyon denklemine en yakın tahmin CMRI denklemine aittir. CMRI denklemi $\mathrm{R}^{2}$ değerinin Çizelge 7'deki ilk 4 denklemden daha yüksek olmamasına rağmen, bu 
Çizelge 7. Farklı regresyon yaklaşımlarının karşılaştırılması

\begin{tabular}{|l|c|c|c|c|c|c|}
\hline Denklem & OMH & HKOK & VYO & Korelasyon & $\begin{array}{c}\text { Tahminin } \\
\text { standart } \\
\text { hatası }\end{array}$ & $\begin{array}{c}<\mathbf{2 ~ m m / s} \\
\text { tahmin } \\
\text { hatası }\end{array}$ \\
\hline USBM [9] & 4.046 & 5.481 & 55.931 & 0.805 & 5.019 & 14 \\
\hline Langefors-Kihlström [11] & 4.204 & 5.532 & 55.165 & 0.797 & 5.118 & 14 \\
\hline Davies et al. [12] & 4.086 & 5.387 & 60.192 & 0.805 & 5.019 & 16 \\
\hline Ambraseys-Hendron [13] & 4.298 & 5.560 & 54.639 & 0.801 & 5.069 & 14 \\
\hline Indian standards [14] & 5.586 & 7.247 & 24.683 & 0.59 & 6.834 & 9 \\
\hline CMRI [15] & 3.821 & 4.552 & 69.533 & 0.834 & 4.673 & 11 \\
\hline Çok değişkenli regresyon & 3,017 & 4,140 & 74,802 & 0,885 & 3,938 & 21 \\
\hline
\end{tabular}

denklem kullanılarak yapılan tahminde $\mathrm{OMH}$ ve HKOK değerleri çok değişkenli regresyondan sonraki en iyi değerlerdir. Bununla birlikte CMRI denkleminin $2 \mathrm{~mm} / \mathrm{s}$ 'den küçük hata ile tahmin ettiği atım sayısı nispeten düşüktür. Indian Standards denklemi, diğerlerine oranla en başarısız tahmin sonuçlarını vermiştir. USBM, Langefors-Kihlstrom, Davies ve diğ. ve Ambrasesy-Hendron denklemlerinin hata oranları büyük ölçüde birbirine yakındır. Elde edilen korelasyon katsayıları 0,797-0,805 aralığındadır.

Aşağıda Şekil 2'de USBM denklemi kullanılarak tahmin edilen yer sarsıntısı değerleri ile ölçülen değerler arasındaki ilişkiliyi gösteren grafik sunulmuştur. Şekil 3'de ise, çok değişkenli regresyon denkleminin tahminleri ve ölçülen değerler arasındaki ilişki gösterilmektedir.

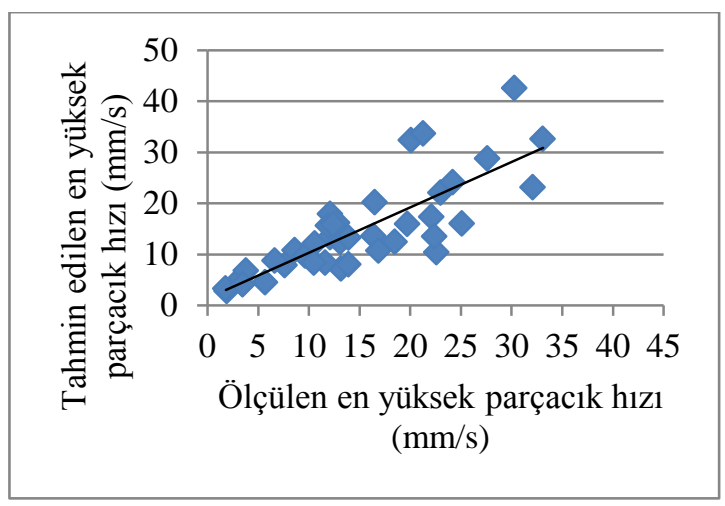

Şekil 2. USBM denklemiyle tahmin edilen ve ölçülen ppv arasındaki ilişki
Geliştirilen regresyon denklemleri 12 bağımsız test atımı üzerinde denenmiştir. Bu atımlar denklemler geliştirilirken kullanılan 39 atımlık veri tabanına dahil değildir. Indian standards [14] yaklaşımı hariç genel olarak denklemlerin başarılı sonuç verdiği söylemek mümkündür. En düşük ortalama tahmin hatası çok değişkenli regresyon denklemi ile elde edilmiştir. $\mathrm{Bu}$ denklem 7 test atımını $2 \mathrm{~mm} / \mathrm{s}$ 'den daha düşük bir hata ile tahmin etmiştir. Ambraseys-Hendron [13] ve CMRI [15] denklemleri çok değişkenli regresyondan sonraki en başarılı sonuçları vermiştir. Tüm bulgular ve ortalama hata değerleri Çizelge 8'de ayrıntılı olarak sunulmuştur.

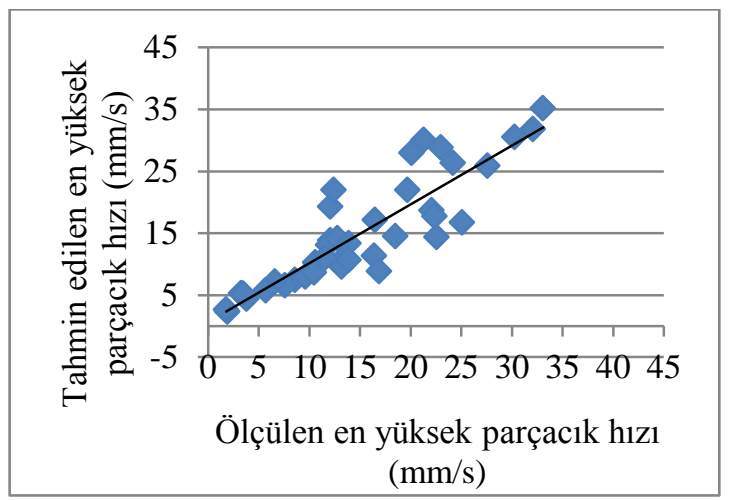

Şekil 3. Çok değişkenli regresyon ile tahmin edilen ve ölçülen ppv arasındaki ilişki

\section{SONUÇLAR VE ÖNERILER}

Patlatma kaynaklı titreşimlerin tahmini amacıyla 
farklı araştırmacıların yaklaşımlarının değerlendirilmesinde fayda vardır. $\mathrm{Bu}$ çalışmada görüldüğü üzere, USBM yaklaşımının dışındaki yaklaşımlar da aynı ölçüde başarılıdır. Ek olarak çok değişkenli regresyon analizinin kullanılması tahmin becerisini kesinlikle artıracaktır. Literatürde bulunan ölçekli mesafeye dayanan denklemler ölçüm mesafesi ve gecikme başına şarj miktarını kullanarak iki parametre ile pratik olarak yer sarsıntısı tahmini yapmaktadır. Patlatma tasarım parametrelerinin kullanıldığı çok değişkenli regresyon modellerinde ayrica modele dahil olacak tasarım parametrelerinin titizlikle ölçülmesi gerekmektedir. Çok değişkenli modele dahil edilen tasarım parametrelerinin sayısının artışı modelleri daha karmaşık hale getirecektir. Araştırmacılar temel patlatma tasarım parametreleri dışındaki parametreleri modellere dahil ederken bu durumu dikkate almalıdırlar. $\mathrm{Bu}$ çalışmada kullanılan çok değişkenli adımsal regresyon tekniği, öne çıkan ve modele dahil edilmesi gereken tasarım parametrelerinin tespiti konusunda araştırmacılara yardımcı olacaktır. Bununla birlikte dilim kalınlığ 1 , delikler arası mesafe, basamak yüksekliği gibi temel patlatma tasarım parametreleri yer sarsıntısı tahmin modelleri kurulurken mümkün olduğunca göz önüne alınmalıdır.

Tahmin probleminde sonuçları değerlendirirken farklı hata ölçüm yaklaşımlarının değerlendirilmesi gerektiği unutulmamalıdır. Bu makalede 6 farklı değerlendirme kriteri kullanılarak sonuçlar irdelenmiştir. Bir denklemin belirlilik katsayısının diğerlerinden yüksek olması, o denklemin kesin olarak diğerlerinden daha başarılı tahmin yaptığı anlamına gelmemektedir. Regresyon denklemleri ile tahmin yaklaşımının en önemli yanı, denklemler geliştirildikten sonra kullanımının son derece kolay ve pratik olmasıdır. Arazide görev yapan mühendislerin farklı seçeneklere sahip olması patlatma kaynaklı yer sarsıntısının tahmini ve önlenmesi konusundaki başarıyı kesinlikle artıracaktır. Son olarak, yer sarsıntısı değerlerinin kayaç özellikleri ile ilişkili olduğunu hatırlatmakta fayda vardır. Geliştirilen regresyon denklemleri arazi şartları değiştikçe yeni ölçülen verilerle revize edilmelidir.

\section{KAYNAKLAR}

1. Kuzu, C., Ergin, H., 2005. An Assessment of Environmental Impacts of Quarry-Blasting Operation: A Case Study in Istanbul, Turkey, Environmental Geology, 48: 211-217.

2. Jimeno, C. L., Jimeno, E. L.,Carcedo, F. J. A., 1995. Drilling and Blasting of Rocks, A. A. Balkema, Brookfield Publication, Rotterdam, 408p.

3. Bhandari, S., 1997. Engineering Rock Blasting Operations, A.A. Balkema, Rotterdam, 375p.

4. Konya, C. J., Walter, E. J., 1990. Surface Blast Design. Prentice Hall, New Jersey, 303p.

5. Singh, T. N., 2004. Artificial Neural Network Approach for Prediction and Control of Ground Vibrations in Mines, Mining Technology (Trans. Inst. Min. Metall. A), 113: 251-256.

6. Segarra, P., Domingo, J. F., Lopez, L. M., Sanchidrian, J. A., \& Ortega, M. F., 2010. Prediction of Near Field Overpressure from Quarry Blasting, Applied Acoustics, 71: 11691176.

7. Tugrul, A., Undul, O., 2006. Engineering Geological Characteristics of Istanbul Greywackes, in: Proceedings of the $10^{\text {th }}$ International Association for Engineering Geology and the Environment (IAEG) Congress, Nottingham, United Kingdom.

8. Uz, B., 2007. Akdağlar Madencilik A.Ş.'nin Ayazağa Köyü Cendere Mevkiinde Yeralan Kırmataş Ocak ve Malzemenin Jeolojik/Yapısal, Minerolojik, Petrografik ve Fizikomekanik Özelliklerinin Etüd ve Değerlendirme Raporu, İTÜ Araştırma Raporu, İTÜ Maden Fakültesi, Jeoloji Mühendisliği Bölümü.

9. Duvall, W.I., Petkof, B., 1959. Spherical Propagation of Explosion Generated Strain Pulses in Rock, US Bureau of Mines, RI 5483, Washington D. C.

10. González-Nicieza, C., Álvarez-Fernandez, M. I, Alvarez-Vigil, A. E., Arias-Prieto, D., López-Gayarre, F., Ramos-Lopez, F. L., 2014. Influence of Depth and Geological Structure on the Transmission of Blast Vibrations, 
Bulletin of Engineering Geology and the Environment, 73: 1211-1223.

11. Langefors, U., Kihlstrom B., 1963. The Modern Technique of Rock Blasting, Wiley Publisher, New York, 405p.

12. Davies, B., Farmer I. W., 1964. Attewell P. B. Ground Vibrations from Shallow Subsurface Blasts", Engineer, 217: 553-559.

13. Ambraseys, N. R., Hendron, A. J., 1968. Dynamic Behavior of Rock Masses. In: Rock Mechanics in Engineering Practice, edi: Stagg, K.G. and O.C. Zeinkiewicz, Wiley, London.

14. Indian Standards Institute, 1973. Criteria for Safety and Design of Structures Subjected to Underground Blast, ISI Bulletin IS-6922.

15. Roy, P. P., 1991. Vibration Control in an Opencast Mine Based on Improved Blast Vibration Predictors. Mining Science and Technology, 12: 157-165.

16. IBM SPSS Statistics Base 20, 2011. IBM Corporation, New York, USA, 314p.

17. Chakraborty, A. K., Raina, A. K., Ramulu, M., Choudhury, P. B., Haldar, A., Sahu, P., C. and Bandopadhyay, C., 2004. Parametric Study to Develop Guidelines for Blast Fragmentation İmprovement in Jointed and Massive Formations, Engineering Geology, 73: 105116.

18. Maleki, H., Zahl, E. G., Dunford, J. P., 1997. Development of a Statistical-Analytical Approach for Assessing Coal Bump Potential, 16th Intl. Conf. on Ground Control in Mining, West Virginia University, USA.

19. Meyers, L. S., Gamst, G. C., Guarino, A. J., 2013. Applied Multivariate Research: Design and Interpretation, SAGE Publications, USA, $1124 \mathrm{p}$.

20. Montgomery, D. C., Peck, E. A., Vining, G. G., 2006. Introduction to Linear Regression Analysis, John Wiley \& Sons Inc, New Jersey, USA, 612p.

21. Öztürkcan, M., 2009. Regresyon Analizi, Maltepe Üniversitesi Yayını, İstanbul, 119p.

22. Hüdaverdi, T., 2012. Application of Multivariate Analysis for Prediction of BlastInduced Ground Vibrations, Soil Dynamics and Earthquake Engineering, 43: 300-308.
23. Grima, M. A., Babuska, R., 1999. Fuzzy Model for the Prediction of Unconfined Compressive Strength of Rock Samples, International Journal of Rock Mechanics and Mining Sciences, 36: 339-349. 